\title{
Dynamics of Polysaccharides and Neutral Lipids during Anther Development in Castor (Ricinus communis)
}

\author{
Dongmei Wei \\ School of Life Science, Taizhou University, Taizhou, Zhejiang 318000, People's Republic of China; \\ and College of Biological Sciences and Technology, Beijing Forestry University, Beijing 100083, \\ People's Republic of China \\ Huimin $\mathrm{Xu}$ and Ruili $\mathrm{Li}^{\mathbf{1}}$ \\ College of Biological Sciences and Technology, Beijing Forestry University, Beijing 100083, People's \\ Republic of China
}

\begin{abstract}
AdDitional INDEX wORDs. anther development, polysaccharides, neutral lipids, Ricinus communis
ABstract. Anthers contain starch and neutral lipids, which have key roles in microspore ontogeny and gametophyte development. In this study, we observed the dynamic changes in starch and neutral lipids in the anther developmental processes of castor (Ricinus communis) by cytochemical methods. Starch grains and neutral lipids presented a regular dynamic distribution during anther development. In young anthers, some neutral lipids accumulated in sporogenous cells, whereas neutral lipids disappeared with microspore growth. At the late microspore stage, starch grains began to accumulate in microspores, and the starch content of bicellular pollen significantly increased after microspore mitosis. At anthesis, starch grains and neutral lipids accumulated in the mature pollen grains. Visible changes occurred in anther wall cells. The epidermis, middle layer, and tapetum were degenerated, and only a single layer of endothecium remained at anthesis. The dynamic variation of starch grains and neutral lipids in tapetal cells was consistent with the changes in microspores and pollen during anther development. All these findings demonstrated that tapetal cells directly interacted with the developing gametophytes. The tapetal cells play an important role in supplying nutritional substances for microspore absorption. Moreover, the endothecium protects the pollen and contributes to anther dehiscence. The results of this study provide a foundation for the further research on sexual reproduction in angiosperms.
\end{abstract}

The anthers of angiosperms are complex male sex organs, and their development is a precisely regulated biological process (Pearce et al., 2015). During anther development, various structural and physiological changes occur, and these changes differ with plant species. One characteristic of anther development is the accumulation of nutrients, generally polysaccharides or neutral lipids, in the pollen pool to fuel the subsequent pollen ontogeny, germination on the stigma surface, and growth of the pollen tube through the style (Cheung and $\mathrm{Wu}, 2007$; Pacini, 1996). Increasing evidence shows that abnormalities in the accumulation and metabolism of nutrients in anthers are associated with pollen sterility (Castro and Clement, 2007; Datta et al., 2002; Ku et al., 2003; Kurusu et al., 2014; Xie et al., 2005).

The dynamic changes in nutrients in anthers are divided into two processes: transportation and transformation. In general, nutrients in the form of sugars are transported from other plant organs to the anthers (Ekici and Dane, 2012). Transported sugars can be directly absorbed by pollen or transformed starch as reserve nutrients in the anther (Bhandari, 1984; Konyar et al., 2013). Sugars can be converted into other molecules, including lipids, which are important structural components for newly synthesized internal membranes, as well as crucial for energy generation and

Received for publication 24 Mar. 2015. Accepted for publication 2 June 2015. This work was supported by the Fundamental Research Funds for the Central Universities (BLX2014-19), the National Natural Science Foundation of China (31170639, 31401149), the Zhejiang Provincial Natural Science Foundation of China (Y3110395), and Program of Domestic Professional Universities to Study for Young Scholar Sponsored by Ministry of Education of China (FX2014116).

${ }^{1}$ Corresponding author. E-mail: liruili@bjfu.edu.cn. storage (Park and Twell, 2001). However, the exact details of these processes are not well understood, and studies on regulatory mechanisms remain quite limited.

Ricinus communis is an important oil crop that is grown in tropical and subtropical regions worldwide. Castor oil is renowned for its medicinal properties and industrial applications (Atsmon, 1989; Negi, 1996). Castor oil is extracted from $R$. communis seeds; therefore, numerous studies have focused on $R$. communis seeds and seedlings (He et al., 2007; Li et al., 2012; Maciel et al., 2011; Ribeiro et al., 2014; Sujatha et al., 2009; Velascoa et al., 2015; Yasur and Rani, 2013). However, detailed studies on anther development and the distribution of reserve substances in the anthers of $R$. communis are scarce. In this study, the histochemical changes occurring in anthers of different stages in $R$. communis were investigated, with special attention to the distribution and amount of polysaccharides and neutral lipids. In addition, the features of nutrient metabolism were analyzed to reveal the reproductive biology of $R$. communis.

\section{Materials and Methods}

Materials. Ricinus communis plants were grown in the fields of the Xiamen University campus in Xiamen, China (lat. $118^{\circ} 32^{\prime} 35^{\prime \prime} \mathrm{E}$, long. $\left.24^{\circ} 61^{\prime} 18^{\prime \prime} \mathrm{N}\right)$. Fresh anthers from staminate buds of different sizes were squashed and observed under a microscope to determine the exact stage of microsporogenesis during the months of November through December.

Preparation and STAINING OF RESIN-EMBEDded SEMITHIN SECTIONS. A minimum of 20 anthers at each stage were collected 
from different staminate buds and fixed with $2.5 \%(\mathrm{v} / \mathrm{v})$ glutaraldehyde in $0.1 \mathrm{M}$ phosphate buffer $(\mathrm{pH} \mathrm{7)}$ for $4 \mathrm{~h}$ at room temperature. After three 20-min rinses with phosphate buffer, anthers were postfixed with $1 \%(\mathrm{w} / \mathrm{v})$ osmium tetroxide in the same buffer for $16 \mathrm{~h}$ at $4{ }^{\circ} \mathrm{C}$. After three more 20 -min rinses, anthers were dehydrated with a graded acetone series $(10 \%$ to $90 \%$ acetone $20 \mathrm{~min}$ each, $100 \%$ acetone three times $30 \mathrm{~min}$ each) and embedded in Epon812 resin (Structure Probe, West Chester, PA).

Embedded anthers were cut into semithin (1 $\mu \mathrm{m})$ sections with an ultramicrotome (Ultracut R 705930; Leica Microsystems, Wien, Austria) and placed on glass slides. Sections were labeled with $0.5 \%$ (w/v) basic fuchsin (85734-3; SigmaAldrich, St. Louis, MO) based on the periodic acid-Schiff (PAS) reaction for $30 \mathrm{~min}$ at room temperature as previously described by $\mathrm{Hu}$ and $\mathrm{Xu}$ (1990). Polysaccharides and starch grains, in particular, were stained red. Sections were then counterstained with $0.3 \%$ (w/v) Sudan Black B (19966-4, Sigma-Aldrich) for $30 \mathrm{~min}$ at $60{ }^{\circ} \mathrm{C}$ to detect lipid droplets, which were stained black. All sections were observed and photographed with a research microscope (DMR; Leica, Deerfield, IL).

\section{Results}

Ricinus communis has unisexual flowers and is monoecious, with staminate flowers located at the base of the inflorescence and pistillate flowers at the top (Fig. 1A). A staminate flower can generally produce over 100 stamens (Fig. 1B). According to the developmental characteristics of pollen, anthers are divided into seven stages: sporogenous cell, microspore mother cell (MMC), tetrad, early microspore, late microspore, early bicellular pollen, and mature pollen. In each stage, staminate buds have different sizes (Fig. 1C), and anthers with different staminate buds display distinct morphological features (Fig. 1D). Unlike most angiosperms with tetrasporangiate anthers, those of $R$. communis are bisporangiate (Fig. 1E).

Following transverse sectioning, $R$. communis anthers from different developmental stages could be divided into anther wall sections or loculus sections, which contain MMCs or pollen grains.

Sporogenous Cell STAGe. The youngest anthers possess differentiated sporogenous cells in the anther center and four layers of cells in the anther wall. Sporogenous cells have an indefinite form and are larger than the surrounding anther wall cells. The ectoentad refers to the four anther cell wall layers, namely, the epidermis, endothecium, middle layer, and tapetum (Fig. 1E). The epidermis, endothecium, and middle layer cells displayed higher vacuolization than the innermost tapetal cells. Therefore, sporogenous and anther wall cells were easily distinguished because tapetal cells had a higher cytoplasmic density than inner sporogenous cells and the other three anther wall cells. Another evident feature of sporogenous cells was the accumulation of some neutral lipids. By contrast, no neutral lipids or starch had accumulated in the epidermis, endothecium, or middle layer cells, and their accumulation was minimal in tapetal cells (Fig. 1E).

MMC STAGE. Two evident changes occurred during the transition from sporogenous cells to MMC: 1) the loosening of the sporogenous cell arrangement, which produced large intercellular spaces between cells; 2) the production of a thick PASpositive callose wall layer that surrounded the MMC (Fig. 1F).
Neutral lipid droplets in the cytoplasm of MMCs became smaller in size and fewer in number. Vacuolization in the epidermis, endothecium, and middle layer cells remained high, but no starch or neutral lipids were visible in these cells. Meanwhile, vacuolization increased in tapetal cells, and both starch (red) and neutral lipids (black) were visibly increased (Fig. 1F).

Microspore Tetrad STAGE. Meiosis in $R$. communis MMCs is simultaneous. Four tetrahedral microspores were observed to be surrounded by the PAS-positive callose wall, and the microspore cytoplasm contained some neutral lipids (Fig. 1G). Endothecium cells of the anther wall grew significantly larger during this stage, and vacuolization significantly increased. Tapetal cells decreased in size as the large vacuoles disappeared and the cytoplasm increased in density. Some starches were still visible at this stage, but neutral lipids were not present (Fig. 1G).

EARLY MICROSPORE STAGE. When the callose wall of the tetrad is dissolved, the four microspores are released and the free microspores are markedly larger. The main characteristic of early microspores is the location of nuclei in the cell center. During this stage, microspores formed a cellulose intine that was PAS positive, whereas the pollen exine was not yet formed. The nucleolus was also PAS positive, thereby indicating the presence of polysaccharides. The neutral lipid content of the microspores declined compared with that of the tetrad microspores, and starch started to appear (Fig. 1H).

Cells of the anther wall underwent some morphological changes during this stage. Endothecium cells remained large in size with high vacuolization. By contrast, epidermis and middle layer cells were compressed into a thin layer and were only visible in some parts of the anther wall. The boundary of tapetal cells became indistinct. The cytoplasm of these cells became disorganized, and vacuoles began to reappear. The starch content increased, and a few small neutral lipid droplets were visible in the tapetal cytoplasm (Fig. 1H).

LATE MICROSPORE STAGE. A feature of microspore development is the formation of a large vacuole, which pushes the microspore nucleus to the cell periphery to generate cell polarity (Fig. 2A). The polarity determines whether microspores become male gametophytes. At this stage, the large vacuole takes up almost the entire cellular volume; hence, this stage is also known as the vacuolated microspore stage. On the surface of the redstained cellulose intine, a layer of pollen exine was formed (Fig. 2A). Late microspores contained no neutral lipids, but a few starch granules were present in the narrow cytoplasmic zone. During this stage, the cells of the anther wall underwent noticeable modifications. The epidermal cells completely disappeared, whereas the outermost endothecium layer thickened. Starch and neutral lipids were not detected in tapetal cells, and the morphology of these cells was unclear because of the low density of the cytoplasm. In some parts of the tapetum, pollen grains were found inserted in the tapetal cells; a large amount of material was visible between the pollen grains in the anther loculus (Fig. 2A).

Bicellular pollen Stage. After microspore mitosis, the bicellular pollen grain contains a small generative cell and a large vegetative cell. The large vacuole in the vegetative cell began to decompose at this stage, and several small vacuoles appeared in the larger vacuole. The smaller vacuole membrane was stained darker, which indicated the higher lipid content of the vacuole membrane. Starch grains were abundant in the vegetative cytoplasm, but neutral lipids were much less abundant (Fig. 2B). Following the disappearance of the large vacuole of vegetative cells, the nucleus migrated to the cell 

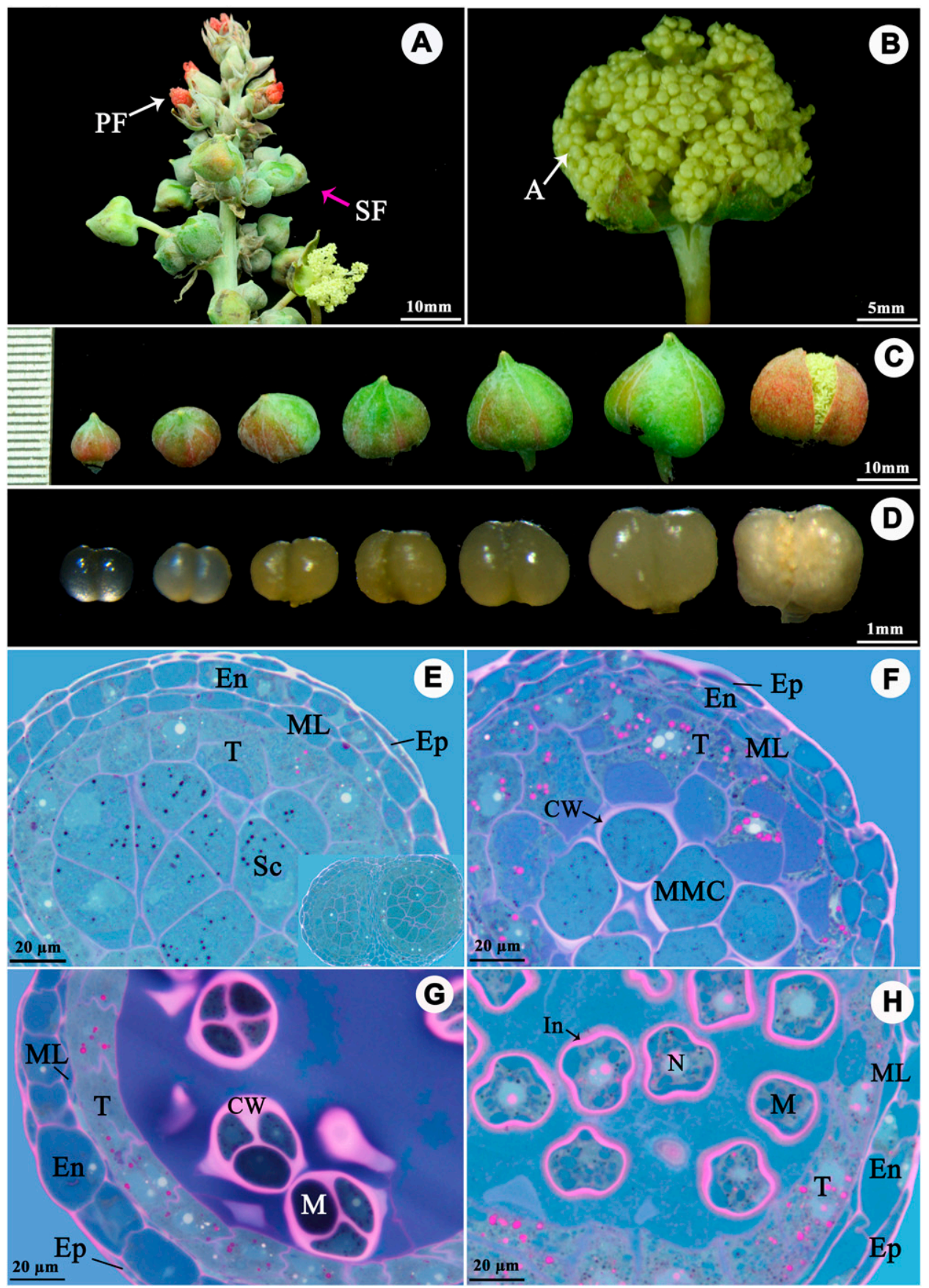

Fig. 1. Morphology of inflorescences, pistillate flowers, staminate flowers, and anthers of Ricinus communis, as well as the starch and lipid distribution in young anthers. (A) Inflorescence of $R$. communis. Pistillate flowers (white arrow) are located near the top, and staminate flowers (red arrow) are at the base. (B) Staminate flower bud showing hundreds of anthers. (C) Staminate flower buds during the seven developmental stages: sporogenous cell, microspore mother cell (MMC), tetrad, early microspore, late microspore, early bicellular pollen, and mature pollen. (D) Anthers during the seven stages. (E) Transverse section of an anther at the sporogenous cell stage. Neutral lipids (stained black) are evident in the center of sporogenous cells, and some starch (stained red) is visible in tapetal cells. (F) MMC stage. MMCs are wrapped in red callose walls, and neutral lipids are visible in the cytoplasm. Limited starch and neutral lipids are present in tapetal cells. (G) The tetrad stage is characterized by four microspores wrapped in red callose walls, and some neutral lipids are present in the microspores. Tapetal cells decrease in size, and very little starch is visible in the cytoplasm. (H) During the early microspore stage, free microspores form the red pollen intine. Neutral lipids are now completely absent from the microspores, and more starch is visible in tapetal cells; $\mathrm{A}=$ anther, En = endothecium, $\mathrm{CW}=$ callose wall, $\mathrm{Ep}=$ epidermis, $\mathrm{In}=$ intine, $\mathrm{M}=$ microspore, $\mathrm{ML}=$ middle layer, $\mathrm{MMC}=$ microspore mother cell, $\mathrm{N}=$ nucleus, $\mathrm{PF}=$ pistillate flower, $\mathrm{SF}=$ staminate flower, $\mathrm{SC}=$ sporogenous cell, $\mathrm{T}$ = tapetum; bars: (A, C) $10 \mathrm{~mm},(\mathbf{B}) 5 \mathrm{~mm},(\mathbf{D}) 1 \mathrm{~mm},(\mathbf{E}, \mathbf{F}, \mathbf{G}, \mathbf{H}) 20 \mu \mathrm{m}$. center and the amount of starches increased. Endothecium cells underwent radial wall thickening, but polysaccharides were not present in these cells. The degenerated tapetal cells contained some vacuoles, and neutral lipids were present in the cytoplasm (Fig. 2C). The generative cell was still attached to the pollen intine, whereas the cytoplasm contained no starch or neutral lipids, although a lipid layer was visible on the cell surface (Fig. 2D). As anther development progressed, endothecium cells did not undergo any remarkable changes, whereas tapetal cells were completely degenerated. Cells of the middle layer became larger but did not accumulate starches or neutral lipids. Starches continued to increase in pollen (Fig. 2E). The generative cell departed from the pollen intine and migrated to the center of the vegetative cell to settle beside the vegetative nucleus (Fig. 2F).

Mature pollen stage. As the bracteoles of the staminal flower break, pollen grains reach maturity and prepare for pollination. During this stage, middle layer cells of the anther wall disappeared, thereby leaving a single layer of endothecium cells that exhibited remarkable radial and inner tangential wall thickening (Fig. 2G). In mature pollen, the lipid content markedly increased, whereas the starch content declined (Fig. 2H). Therefore, neutral lipids were the main nutrient reserve in mature $R$. communis pollen.

\section{Discussion}

The development of anthers in angiosperms involves the coordinated interaction of several types of tissues and cells to produce tricellular male gametophytes (Goldberg et al., 1993). To ensure sufficient energy and material for pollen germination, mature pollen accumulates abundant nutrients in the form of starch grains and/ or neutral lipids. By contrast, protein reserves are not as abundant as they are in the seeds (Pacini, 1996). In this investigation, we observed that the starch grains and neutral lipids were highly accumulated in the mature pollen grains of $R$. communis. This result was similar to that reported for Magnolia Xsoulangeana, Ipomoea 

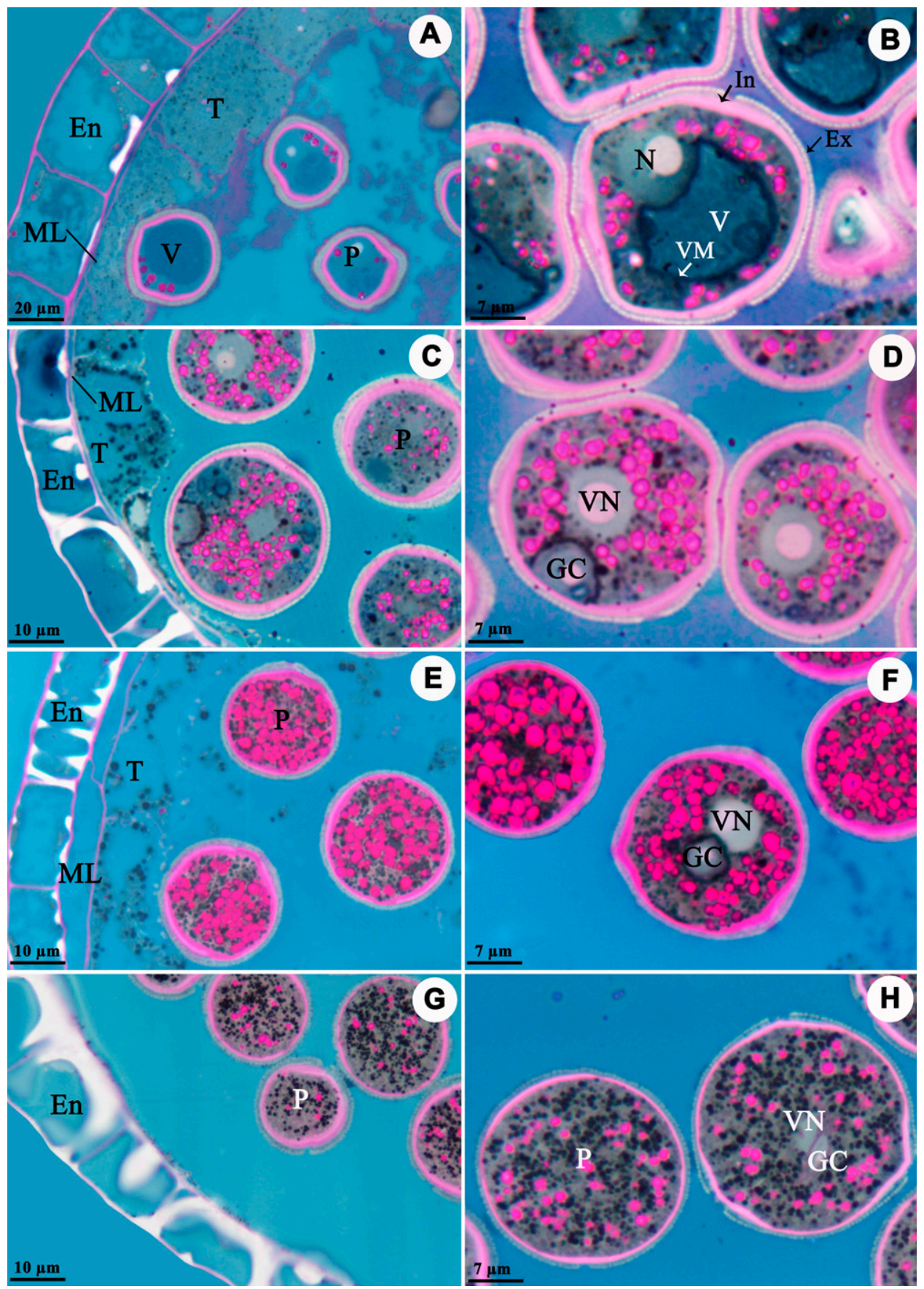

Fig. 2. Starch and lipid distribution in older Ricinus communis anthers. (A) In late microspore stage anthers, a large vacuole occupies almost the entire cellular volume, and epidermal cells have degenerated. Some starch appears in the vacuolated microspore cytoplasm, whereas small amounts of neutral lipids are present in tapetal cells. (B) During the early bicellular stage, the large vacuole in bicellular pollen decomposes and larger amounts of starch are present in the pollen. (C) Following anther development, the epidermis of the anther wall completely degenerates, and endothecium cells undergo radial and inner tangential wall thickening. Tapetal cells degenerate and some neutral lipids are visible in their cytoplasm. (D) The large vacuole in the vegetative cell of bicellular pollen completely disappears, and the smaller generative cell on the pollen wall is visible. Starch increases in the vegetative cell, and some neutral lipids are located on the generative cell surface, but starch and neutral lipids are not present in the center of the cell. (E) Following further anther development, tapetal cells are completely degenerated and middle layer cells become enlarged. (F) The generative cell dissociates from the pollen wall and moves into the center of the vegetative cell. Starch is still predominant in pollen. (G) At anthesis, the anther wall consists of a single layer of endothecium cells. (H) Mature pollen is filled with neutral lipids, and the starch content is sharply decreased; $\mathrm{En}=$ endothecium, $\mathrm{Ex}=$ exine, $\mathrm{GC}=$ generative cell, $\mathrm{In}=$ intine, $\mathrm{ML}=$ middle layer, $\mathrm{N}=$ nucleus, $\mathrm{P}=$ pollen, $\mathrm{T}=$ tapetum, $\mathrm{V}=$ vacuole, $\mathrm{VC}=$ vegetative cell, $\mathrm{VM}=$ vacuolar membrane; bars: (A) $20 \mu \mathrm{m},(\mathbf{B}, \mathbf{D}, \mathbf{F}, \mathbf{H}) 7 \mu \mathrm{m},(\mathbf{C}, \mathbf{E}, \mathbf{G}) 10 \mu \mathrm{m}$. cairica, and Amomum villosum (Dinis and Coutinho, 2009; Lin et al., 2014; Liu et al., 2011), but differed from those for Mangifera indica and wheat (Triticum aestivum) store starch grains, Brassica campestris stores lipid exclusively, and Campsis radicans stores starch grains, neutral lipids and protein in the pollen grains (Konyar et al., 2013; Li et al., 2013; Ma et al., 2011; Xie et al., 2005). These results suggested that nutrient accumulation in mature pollen grains was a species-specific characteristic.

Sugars from plant vegetative organs are the main fuel for anther development. The regulation of this process has not been reported in detail. Sugars can be transferred across anther somatic tissues to microspores and pollens (Ekici and Dane, 2012; Konyar et al., 2013). In this study, we found that starch grain deposition in tapetal cells showed dynamic variation. From the sporogenous cell stage to the early microspore stage, starch grains gradually increased in tapetal cells, but there were no starch grains present in the microspores. On the basis of the PASpositive reaction of the callose wall and pollen intine, and starch may be transformed into other types of polysaccharides (Castro and Clement, 2007). Therefore, starch grains were involved in the formation of the callose wall and pollen intine. However, previous investigations demonstrated that the intine layer is deposited after mitosis (Sharma et al., 2015b). At the late microspore stage, starch grains began to accumulate in the microspores, and plentiful starch grains were present in the bicellular pollen. Given that generative and sperm cells are in a state of higher osmolality (Deng et al., 2012), we suppose that the high osmolality of the anther loculus is essential to allow anthers and pollen to absorb sugars from plant vegetative organs.

The transformation pattern of nutrient reserves is complex and variable during anther development in different plant species. Polysaccharides can convert into neutral lipids and vice versa. In plants, such as $M$. indica and wheat, sugar is transferred from vegetative plant organs to anthers, mature pollen only accumulates starch, and material conversion does not occur $(\mathrm{Li}$ 
et al., 2013; Ma et al., 2011). The mature pollen of B. campestris exclusively stores lipid, presumably by converting absorbed sugars (Xie et al., 2005). Conversely, the pollen of $M$. Xsoulangeana can transform neutral lipids into starch (Dinis and Coutinho, 2009). In I. cairica and A. villosum, both neutral lipids and starch accumulate in mature pollen grains, thereby suggesting the conversion of sugar into neutral lipids (Lin et al., 2014; Liu et al., 2011). The conversion of polysaccharides into neutral lipids and proteins occurs in the $C$. radicans pollen grains (Konyar et al., 2013). In the present study, we found that starch began to accumulate in vacuolated microspores of $R$. communis, which differed from the reports that nutrient reserves begin to accumulate in $M$. indica, wheat, $B$. campestris, $M$. $\times$ soulangeana, and I. cairica at the bicellular pollen stage, as well as in A. villosum at the MMC stage. We also observed that microspores absorbed neutral lipids from tapetal cells, and pollen was filled with starch grains and not neutral lipids at the bicellular pollen stage. Moreover, neutral lipids partially appeared to replace starch grains at the mature pollen stage. These results indicated the ability to transform neutral lipids into starch grains and vice versa in pollen of $R$. communis. Given the changes in starch grains and neutral lipids in developing anthers, the dynamic distribution of starch granules and neutral lipids in anthers of $R$. communis and the exact time of transformation of nutrient reserves are characteristic features of $R$. communis.

Tapetal cells of the anther wall form the innermost layer that directly interacts with the developing gametophytes (Pacini et al., 1985). The tapetum plays an important role in the exchange of nutritional, structural, or regulatory compounds between the sporophytic anther tissues and developing male gametophytes (Schrauwen et al., 1996). The mutation of a gene in tapetal cells affects pollen wall formation (Ariizumi et al., 2004). In our study, the morphological change in tapetal cells occurred at the late microspore stage. The cytoplasm density increased and numerous neutral lipids were present in tapetal cells, which implied that these characteristics were closely related to active lipid metabolism in tapetal cells. The sporopollenin exine of pollen is made of neutral lipids (Samuels et al., 2008; Wilson and Zhang, 2009). Our experiments showed that the pollen wall was formed from two layers, namely, the cellulosic intine and sporopollenin exine. During microspore development of $R$. communis, the cellulosic intine was first to become visible and tapetal cells were stained red, thereby indicating polysaccharide accumulation. Pollen drives intine formation (Yadav et al., 2014), so sugars in tapetal cells are absorbed by pollen to construct the cellulosic intine. Following microspore development, the second sporopollenin exine layer was formed from neutral lipids. Moreover, the sugar content in tapetal cells decreased during this stage, whereas the lipid content increased. The lipid metabolism of tapetal cells was involved in exine formation. The dynamics of sugars and neutral lipids in tapetal cells displayed distinct spatiotemporal characteristics that corresponded to pollen development.

The epidermis and endothecium were previously reported to remain in mature anthers at anthesis, whereas the tapetum and middle layers were completely degraded during anther development (Sharma et al., 2015a). Our present results showed that the epidermis of $R$. communis anthers was similarly degenerated. Mature anthers only had a single layer of remaining endothecium cells, which suggested these cells could protect pollen development. Furthermore, we observed visible thickening in the radial and inner tangential walls, which produced unequal strength upon exposure to air at anthesis. The anther wall usually has a single layer of endothecium cells. However, $A$. villosum anthers were recently shown to contain several layers (Lin et al., 2014). These differences are another example of endothecium diversity in anther development.

\section{Conclusions}

The pattern of metabolism and distribution of starch and lipids varies in anthers of different plants. The histochemical analysis of the anthers in $R$. communis presented in this study has expanded our knowledge of this variety involved in crucial development processes such as late microspores stage, late bicellular stage and anthesis. Importantly, we observed that the accumulation of reserve substances began at the late microspores stage, and plentiful amount of starch granules and lipids were stored in pollens at anthesis. Moreover, we found the cytoplasm of tapetal cells, which supplied nutrient substance for pollens, was filled with lipids from the late microspore stage to the late bicellular stage. These results shed light on our understanding of the physiological changes involved in pollens development.

\section{Literature Cited}

Ariizumi, T., K. Hatakeyama, K. Hinata, R. Inatsugi, I. Nishida, S. Sato, T. Kato, S. Tabata, and K. Toriyama. 2004. Disruption of the novel plant protein NEF1 affects lipid accumulation in the plastids of the tapetum and exine formation of pollen, resulting in male sterility in Arabidopsis thaliana. Plant J. 39:170-181.

Atsmon, D. 1989. Castor, p. 348-447. In: G. Robbelen, R.K. Downey, and A. Ashri (eds.). Oil crops of the world. McGraw Hill, New York, NY. Bhandari, N.N. 1984. The microsporangium, p. 53-121. In: B.M. Johri (ed.). Embryology of angiosperms. Springer-Verlag, Berlin, Germany.

Castro, A.J. and C. Clement. 2007. Sucrose and starch catabolism in the anther of Lilium during its development: A comparative study among the anther wall, locular fluid and microspore/pollen fractions. Planta 225:1573-1582.

Cheung, A.Y. and H.M. Wu. 2007. Structural and functional compartmentalization in pollen tubes. J. Expt. Bot. 58:75-82.

Datta, R., K.C. Chamusco, and P.S. Chourey. 2002. Starch biosynthesis during pollen maturation is associated with altered patterns of gene expression in maize. Plant Physiol. 130:1645-1656.

Deng, H., Y.Y. Wang, X.Y. Zhu, and H.Q. Tian. 2012. Generative and sperm cell isolation in Bauhinia blakeane (Fabaceae). Ann. Bot. Fenn. 49:1-6.

Dinis, A.M. and A.P. Coutinho. 2009. Interaction of lipid bodies with other cell organelles in the maturing pollen of Magnolia $\times$ soulangeana (Magnoliaceae). Protoplasma 238:35-46.

Ekici, N. and F. Dane. 2012. Some histochemical features of anther wall of Leucojum aestivum (Amaryllidaceae) during pollen development. Biologia 67:857-866.

Goldberg, R.B., T.P. Beals, and P.M. Sanders. 1993. Anther development: Basic principles and practical applications. Plant Cell 5:1217-1229.

He, X.H., G.Q. Chen, S.T. Kang, and T.A. McKeon. 2007. Ricinus communis contains an acyl-CoA synthetase that preferentially activates ricinoleate to its CoA thioester. Lipids 42:931-938.

Hu, S.Y. and L.Y. Xu. 1990. A cytochemical technique for demonstration of lipid drops, starch and protein bodies in thick resin sections. Acta Bot. Sin. 32:841-846.

Konyar, S.T., F. Dane, and S. Tutuncu. 2013. Distribution of insoluble polysaccharides, neutral lipids, and proteins in the developing anthers of Campsis radicans (L.) Seem (Bignoniaceae). Plant Syst. Evol. 299:743-760. 
Kurusu, T., T. Koyano, S. Hanamata, T. Kubo, Y. Noguchi, C. Yagi, N. Nagata, T. Yamamoto, T. Ohnishi, Y. Okazaki, N. Kitahata, D. Ando, M. Ishikawa, S. Wada, A. Miyao, H. Hirochika, H. Shimada, A. Makino, K. Saito, H. Ishida, T. Kinoshita, N. Kurata, and K. Kuchitsu. 2014. OsATG7 is required for autophagy-dependent lipid metabolism in rice postmeiotic anther development. Autophagy 10:878-888.

$\mathrm{Ku}, \mathrm{S}$., H. Yoon, H.S. Su, and Y.Y. Chung. 2003. Male-sterility of thermosensitive genic male-sterile rice is associated with premature programmed cell death of the tapetum. Planta 217:559-565.

Li, D.X., X.L. Deng, G. Li, and Z.G. Ru. 2013. Cytochemical observation of fertile and sterile anthers of a thermo-sensitive genic male-sterile wheat (Triticum astivum L). Acta Agron. Sin. 39:878-884.

Li, H.L., L.B. Zhang, D. Guo, C.Z. Li, and S.Q. Peng. 2012. Identification and expression profiles of the WRKY transcription factor family in Ricinus communis. Gene 503:248-253.

Lin, M.Z., Y. Zhu, S.J. Yang, D.M. Wei, and H.Q. Tian. 2014. Cytochemical study of developing anthers of Amomum villosum Lour. Flora 209:567-570.

Liu, R.S., Y.L. Qiu, D.M. Wei, H.H. Liu, X.Y. Zhu, H.Q. Tian, and J.A. Teixeira da Silva. 2011. Distribution of starch and neutral lipids in the developing anthers of Ipomoea cairica. Ann. Bot. Fenn. 48:256-262.

Maciel, F.M., C.M.C. Salles, C.A. Retamal, V.M. Gomes, and O.L.T. Machado. 2011. Identification and partial characterization of two cysteine proteases from castor bean leaves (Ricinus communis L.) activated by wounding and methyl jasmonate stress. Acta Physiol. Plant. 33:1867-1875.

Ma, Y., W. Deng, and H.Q. Tian. 2011. Cytochemical study on the developing anthers of Mangifera indica. Guihaia 31:338-341.

Negi, S.S. 1996. Castor (Ricinus communis L.) seed, oil and meal, p. 355-359. In: E. Nwokolo, and J. Smartt (eds.). Food and feed from legumes and oilseeds. Chapman \& Hall, London, UK.

Pacini, E. 1996. Types and meaning of pollen carbohydrate reserves. Sex. Plant Reprod. 9:362-366.

Pacini, E., G.G. Franchi, and M. Hesse. 1985. The tapetum: Its form, function and possible phylogeny in Embryophyta. Plant Syst. Evol. 149:155-185.

Park, S.K. and D. Twell. 2001. Novel patterns of ectopic cell plate growth and lipid body distribution in the Arabidopsis gemini pollen 1 mutant. Plant Physiol. 126:899-909.
Pearce, S., A. Ferguson, J. King, and Z.A. Wilson. 2015. FlowerNet: A gene expression correlation network for anther and pollen development. Plant Physiol. 167:1717-1730.

Ribeiro, P.R., L.G. Fernandez, R.D.D. Castro, W. Ligterink, and H.W. M. Hilhorst. 2014. Physiological and biochemical responses of Ricinus communis seedlings to different temperatures: A metabolomics approach. BMC Plant Biol. 14:223-236.

Samuels, L., L. Kunst, and R. Jetter. 2008. Sealing plant surfaces: Cuticular wax formation by epidermal cells. Annu. Rev. Plant Biol. 59:683-707.

Schrauwen, J.A.M., T. Mettenmeyer, A.F. Croes, and G.J. Wullems. 1996. Tapetum-specific genes: What role do they play in male gametophyte development? Acta Botanica Neerlandica 45:1-15.

Sharma, A., M.B. Singh, and P.L. Bhalla. 2015a. Anther ontogeny in Brachypodium distachyon. Protoplasma 252:439-450.

Sharma, A., M.B. Singh, and P.L. Bhalla. 2015b. Ultrastructure of microsporogenesis and microgametogenesis in Brachypodium distachyon. Protoplasma online, DOI 10.1007/S00709-0150793-6.

Sujatha, M., M. Lakshminarayana, M. Tarakeswari, P.K. Singh, and R. Tuli. 2009. Expression of the crylEC gene in castor (Ricinus communis L.) confers field resistance to tobacco caterpillar (Spodoptera litura Fabr) and castor semilooper (Achoea janata L.). Plant Cell Rep. 28:935-946.

Velascoa, L., A. Fernandez-Cuesta, M.J. Pascual-Villalobos, and J.M. Fernandez-Martínez. 2015. Variability of seed quality traits in wild and semi-wild accessions of castor collected in Spain. Ind. Crops Prod. 65:203-209.

Wilson, Z.A. and D.B. Zhang. 2009. From Arabidopsis to rice: pathways in pollen development. J. Expt. Bot. 60:1479-1492.

Xie, C.T., Y.H. Yang, X.Y. Zhu, and H.Q. Tian. 2005. Cytochemical investigation of genic male-sterility in chinese cabbage. Sex. Plant Reprod. 18:75-80.

Yadav, V., I. Molina, K. Ranathunge, I.Q. Castillo, S.J. Rothstein, and J.W. Reed. 2014. ABCG transporters are required for suberin and pollen wall extracellular barriers in Arabidopsis. Plant Cell 26:3569-3588.

Yasur, J. and P.U. Rani. 2013. Environmental effects of nanosilver: impact on castor seed germination, seedling growth, and plant physiology. Environ. Sci. Pollution Res. 20:8636-8648. 